\title{
Targets and outcomes
}

Many of us working in government health systems will have become used to the focus on meeting targets and demonstrating satisfactory treatment outcomes. This approach in principle should be welcomed because at its heart is the desire to improve the lives of our patients and their families. Often, however, targets and outcomes can be the subject of political interference, and hence become less pure in their utility. Many would feel that in the British National Health Service (NHS) political interference is a particular issue, with the diagnosis of cancer being one of the most sensitive areas. In the UK, the NHS has established a 'two-week wait' referral service for patients with symptoms and signs that may indicate the development of cancer. This is aimed at reducing the time between attendance in primary care and referral to a hospital specialist. In this issue, an article by Bethell and Leftwick aimed to identify areas for improvement in the two-week wait service as it applies to head and neck cancer. ${ }^{1}$ The article focused on clinicians' opinions of the service, and found that 59 per cent of general practitioners and 86 per cent of head and neck surgeons felt that the system could be improved. This article adds to others that suggest ways of streamlining the diagnosis of head and neck cancer, particularly when patients present with neck masses. ${ }^{2,3}$ Elsewhere in this issue, from a research perspective in head and neck cancer, Harris and colleagues review the literature on the prognostic value of circulating and disseminated tumour cells, concluding that their detection may become an important clinical tool. ${ }^{4}$ This review supports the preliminary results reported in The Journal of Laryngology \& Otology by He and colleagues, in which circulating tumour cells were detected in patients with advanced-stage head and neck cancer using the CellSearch system. ${ }^{5}$

Moving onto outcomes, the area of our specialty most conducive to this approach is almost certainly otology, with outcomes of surgery in particular being measured using audiometry. ENT-UK, through Matthew Yung, has introduced a national audit of middle-ear surgery that uses myringoplasty as a benchmark procedure. In this issue, the outcomes of the UK myringoplasty audit are presented. ${ }^{6}$ The article reports an overall closure rate for myringoplasty of 89.5 per cent, and concludes that myringoplasty is a safe and effective procedure. The potential criticism of this audit as a reflection of national practice is that its use is not compulsory at the present time. With revalidation, however, surgeons who do not benchmark their results against others are likely to come under increasing scrutiny. In another article in this issue, Joseph and colleagues use quality of life (QoL) measures to assess the utility of mastoid surgery in chronic otitis media. ${ }^{7}$ The principle instrument used was the Glasgow Benefit Inventory. ${ }^{8}$ Interestingly, they found that mastoid surgery for chronic otitis media in most patients did not produce an increase in QoL. This finding differs from a study in a low-income country, which showed significant improvement in QoL in patients who underwent middle-ear surgery. ${ }^{9}$ Possibly the setting and patient expectations account for the different outcomes in these studies.

\section{ROBIN YOUNGS EDWARD FISHER \\ Senior Editors}

\section{References}

1 Bethell GS, Leftwick P. Views of general practitioners and head and neck surgeons on the referral system for suspected cancer: a survey. J Laryngol Otol 2015;129:893-7

2 Dimbleby G, Golding L, Al Hamarneh O, Ahmad I. Cutting cancer waiting times: streamlining cervical lymph node biopsy. J Laryngol Otol 2013;127:1007-11

3 Raja H, Pabla L, Wheatley H, Farr MR. Lymphoma presenting as neck lumps: causes of waiting time target breaches and potential solutions. J Laryngol Otol 2013;127:1111-15

4 Harris AT, Derbyshire S, Wilson J, Loh C, Kinshuck AJ, Attlmayr B et al. Circulating and disseminated tumour cells in head and neck cancer. J Laryngol Otol 2015;129:826-30

$5 \mathrm{He} \mathrm{S}$, Li P, He S, Long T, Zhang N, Fang J et al. Detection of circulating tumour cells with the CellSearch system in patients with advanced-stage head and neck cancer: preliminary results. J Laryngol Otol 2013;127:788-93

6 Phillips JS, Yung MW, Nunney I. Myringoplasty outcomes in the UK. J Laryngol Otol 2015;129:860-4

7 Joseph J, Miles A, Ifeacho S, Patel N, Shaida A, Gatland D et al. Comparison of quality of life outcomes following different mastoid surgery techniques. J Laryngol Otol 2015;129:835-9

8 Maile EJ, Youngs R. Quality of life measures in otitis media. J Laryngol Otol 2013;127:442-7

9 Maile EJ, Tharu PB, Blanchford HL, Edmiston R, Youngs R. Quality of life of Nepali patients with ear disease before and after corrective surgery. Trop Med Int Health 2015;20:1041-7 